\title{
A Versatilidade dos Procedimentos Terapêuticos Valvulares Percutâneos
}

\author{
Áurea J. Chaves
}

$\mathbf{N}$ os últimos anos, temos testemunhado a crescente versatilidade do tratamento valvular percutâneo, desde os procedimentos de dilatação por balão até as técnicas mais sofisticadas, como o implante valvular aórtico e a anuloplastia mitral. Esta edição traz três importantes contribuições que exploram o amplo espectro terapêutico contemporâneo dessas intervenções.

Gomes et al., do Instituto Dante Pazzanese de Cardiologia (São Paulo, SP), relatam os resultados, obtidos em sua grande casuística, de pacientes submetidos a procedimentos de valvotomia mitral repetidos, demonstrando que uma segunda ou terceira intervenções, quando indicadas, têm bons resultados. Ted Feldman, do Evanston Hospital (Illinois, Estados Unidos), em um editorial bem fundamentado, lembra os resultados duráveis da valvotomia mitral, os resultados similares das várias técnicas disponíveis e o uso inadequado do escore de Wilkins na seleção de pacientes para o procedimento.

Hernández-García et al., do Hospital Clínico Universitário (Málaga, Espanha), apresentam os resultados animadores do implante percutâneo de prótese aórtica, por via tanto femoral como subclávia esquerda, em pacientes com estenose aórtica grave e com alto risco cirúrgico. Rogério Sarmento-Leite, do Instituto de Cardiologia (Porto Alegre, RS), comenta em seu editorial o sucesso e a difusão em escala mundial do procedimento, mas aponta os requisitos necessários para a obtenção de bons resultados, como aperfeiçoamento da prótese, necessidade de formação de equipe de atendimento multidisciplinar capacitada, redução dos custos e, principalmente, correta seleção de pacientes.

Gallo Merino et al., do French Hospital (Assunção, Paraguai), trazem, em artigo inédito, os resultados de um estudo first-in-man com nova técnica percutânea de anuloplastia posterior mitral apresentada no EuroPCR de 2009, em Barcelona, Espanha. Descrevem em detalhes o procedimento, destinado ao tratamento da insuficiência mitral funcional, e os resultados iniciais promissores da nova intervenção. Em editorial correspondente, Brandão e Pomerantzeff, do Instituto do Coração (São Paulo, SP), mencionam os benefícios da plastia mitral cirúrgica, com a inerente preservação do aparelho subvalvar, comparada à substituição valvar nos pacientes com insuficiência cardíaca. Reconhecem o ineditismo na técnica percutânea, mas advertem para as limitações atuais, como a impossibilidade de realizar anuloplastia completa ou a possibilidade de distorção das cordas tendíneas, e a necessidade de controle rigoroso dos resultados a médio e longo prazos do novo procedimento.

Saindo da temática do tratamento valvular percutâneo, recebemos, da Fundação Favaloro (Buenos Aires, Argentina), artigo de Fava et al., que trata de uma estratégia híbrida de tratamento que combina, em um mesmo dia, angioplastia carotídea e, a seguir, cirurgia cardiovascular em pacientes clinicamente instáveis. Os resultados obtidos, com taxas de complicações aceitáveis nessa população de complexidade muito aumentada, reproduzem achados de estudos recentemente disponíveis na literatura e encorajam a avaliação dessas estratégias híbridas como nova opção de tratamento em pacientes que apresentem simultaneamente doença cardiovascular com indicação cirúrgica e doença carotídea grave.

Outra contribuição veio do Hospital do Coração de Sobral, Ceará. Carneiro et al. apresentam estudo em que foram randomizados 651 pacientes com angina estável para intervenções coronárias ad hoc ou estagiadas. Trata-se de iniciativa louvável de centro brasileiro, primariamente assistencial, que mostra ser possível a realização de trabalhos metodologicamente impecáveis, bastando para isso determinação de seus dirigentes. Lino Patrício, do Hospital de Santa Marta de Lisboa, Portugal, enaltece os bons resultados alcançados pela estratégia ad hoc em seu editorial, lembrando, no entanto, os cuidados necessários para reproduzir esses achados e o apoio que novas ferramentas, como o Syntax score e a reserva de fluxo fracionada, podem trazer para auxiliar essa decisão.

Publicamos, neste fascículo, simultaneamente com a Revista Brasileira de Cirurgia Cardiovascular, editorial de Gomes e Braile, que analisa os problemas enfrentados recentemente com a heparina não-fracionada, fármaco essencial para garantir os bons resultados das intervenções cardíacas tanto cirúrgicas como percutâneas. Os autores avaliam o impacto causado pela retirada abrupta do mercado do Liquemine, do Laboratório 
Roche, a inadequação das atuais heparinas nacionais de origem bovina e as medidas que a Sociedade Brasileira de Cirurgia Cardiovascular tomou, com o apoio da Agência Nacional de Vigilância Sanitária (ANVISA), para garantir o retorno da heparina de origem suína, que será produzida por quatro fabricantes diferentes, e os cuidados que vão assegurar sua qualidade e padronização.

Por fim, para comemorar os 80 anos do primeiro cateterismo cardíaco, apresentamos Artigo Especial de
Carlos Gottschall, do Instituto de Cardiologia (Porto Alegre, RS), que faz extensa revisão histórica desse período, desde o primeiro procedimento, realizado por Werner Forssmann, passando pelo desenvolvimento dos cateterismos direito e esquerdo, da angiocardiografia, da coronariografia e da angioplastia coronária com o balão, até os resultados mais recentes, com a utilização dos stents farmacológicos.

Áurea J. Chaves Editora 